Histology, Cytology and Embryology (HCE)

\title{
Histomorphological effect of Lamivudine on the Cerebellum of Wistar rats
}

\author{
Aniekan Imo Peter ${ }^{1}$, Kudighe Patrick Udoh ${ }^{2 *}$ and Akpan Udo Ekanem ${ }^{1}$ \\ ${ }^{1}$ Department of Anatomy, University of Uyo, Nigeria \\ ${ }^{2}$ Community Health Officer's Training School, University of Uyo Teaching Hospital, Uyo, Nigeri
}

\begin{abstract}
Lamivudine is an anti-retroviral drug used for the treatment of HIV and hepatitis B. It is one of the essential medicines needed in a basic health system. This study was carried out to investigate the detrimental effect of lamivudine on the cerebellum based on the adverse effects of gait disorders manifested by patients using lamivudine. Twenty male Wistar rats divided into two groups of ten rats each were used for the study. Control group A was administered with $1 \mathrm{ml}$ of distilled water, while treatment group B was treated with $4.28 \mathrm{mg} / \mathrm{kg}$ of lamivudine daily for 30 days. On the $30^{\text {th }}$ day, the rats were euthanized and each cerebellum was harvested immediately. The cerebella were put through routine tissue processing for $\mathrm{H} / \mathrm{E}$ staining and GFAP immunohistochemical method. The resulting specimens were mounted with DPX and viewed under the light microscope at $\times 400$. Photomicrographs showed shrunken Purkinje cells and distorted granular layer in the cerebellum of group B rats while those of group A rats were healthy. Also, image J counting showed reduced number of cells in the lamivudine group. This correlated with the higher staining intensity for GFAP in the granular layer of group B rats suggesting cellular inflammation and damage. More research is needed to ascertain the molecular mechanism of these distortions.
\end{abstract}

\section{Introduction}

Lamivudine (also called 3TC) is a reverse transcriptase inhibitor (nRTI) that inhibits both types (1 and 2) of HIVreverse transcriptase and the reverse transcriptase of hepatitis $B$ virus [1]. It is a cytidine analogue that is phosphorylated to active metabolites within the cell. In its active form, lamivudine competes for incorporation into viral DNA and act as chain terminator in viral DNA synthesis [2]. According to $\mathrm{WHO}$, it is one of the essential medicines in a basic health system [3].

Lamivudine is administered orally and has high absorption rate with bio-availability of about $86 \%$ [4]. It is often administered in combination with other drugs and has been found to restore sensitivity of other drugs to previously resistant HIV [2]. In adition, many combined antiretroviral therapies (cART) containing lamivudine have been reported to be effective in reducing cerebrospinal fluid (CSF) viral load [5]. Treatment of hepatitis $B$ patients shows that lamivudine enhances the seroconversion of e-antigen positive hepatitis $B$ and also improves histological reversal of liver fibrosis [6]. It has also been reported to be used successfully in some Ebola patients during the 2014 Ebola outbreak in Africa [7]. However, long- term use of lamivudine leads to emergence of a resistant hepatitis B virus (YMDD) mutant and HIV-1 patients with concurrent HBV infections have been found to develop resistant to lamivudine [1,8]. In HIV treatment, M184V/I mutation in the reverse transcriptase is linked to high level resistance to lamivudine with slight rebound of the HIV viral load which surges when Lamivudine is completely withdrawn [9].

The effectiveness of lamivudine in suppressing the overall viral load in the system can be attributed to its ability to cross the blood-brain barrier [10]. Access to the CNS allows it to suppress viral replication, mutation and reinfection of the systemic circulation [11,12]. However, like most other HAARTs, the use of Lamivudine has been reported to present several neurological side effects including: headache, dizziness, depression, neuropathy, hypnagogic effects, peripheral paresthesia, hypoesthesia, and peripheral neuropathy [4]. According to a case report by Li et al. long-term use of lamivudine by three patients induced symptoms of Parkinson's disease with mask like facies; hypokinesia with reduced automatic movement and shuffling gait [13]. The report added that these side effects improved considerably when lamivudine was withdrawn. Furthermore, MRI of brain of patients under cART with lamivudine, tenofovir and abacavir shows cerebellar lesions which were not found with other cART lacking lamivudine [14]. These findings suggest a destructive effect of lamivudine to cerebellum. In addition, the elevated levels of lactic acidosis found in patients under lamivudine treatment may lead to cerebellar degeneration as lactic acidosis have been linked to ataxia and slurred speech which are all coordinated by the cerebellum $[15,16]$. Moreover, Stelmashuk, et al. had reported that high acid concentrations induced death of cerebellar granule cells in culture [17].

Due to dearth of literature, this study was done to investigate the histomorphological effect of lamivudine on the cerebellum of Wistar rats.

\section{Methodology}

Twenty male wistar rats were used for the study. The animals were obtained from the animal house of the College of Health Sciences, University of Uyo. They were divided into 2 groups of

Correspondence to: Kudighe Patrick Udoh, Community Health Officers Training School, University of UyoTeaching Hospital, Uyo, Nigeria, E-mail: kudigheudoh@gmail.com

Key words: cerebellum, lamivudine, lactic acidosis, depression, dizziness

Received: June 12, 2017; Accepted: July 14, 2017; Published: July 17, 2017 
10 rats each. Group A served as the control and were administered with $1 \mathrm{ml}$ of distill water, while group B were treated with $4.28 \mathrm{mg} /$ $\mathrm{kg}$ of Lamivudine daily for 30 days. The rats were handled carefully according to the guidelines for the treatment of laboratory rats by National Centre for the Replacement, Refinement, and Reduction of animals in research (NC3Rs). On the 30th day, the rats were euthanized and each cerebellum was harvested immediately.

\section{Animal sacrifice and tissue processing}

Animals were sacrificed using chloroform inhalation and the brain was dissected and the cerebellum was removed. The cerebellum was then dehydrated through graded alcohol. This was to remove excess water inherent in tissues as follows; two changes of $70 \%$ and $95 \%$ alcohol for 2 hours each, 2 changes of 100\% (absolute) alcohol for two hours each. Dehydrated tissues were cleared using 2 changes of xylene ( 5 minutes each). This was followed by impregnation through 2 changes of paraffin wax in the oven at the temperature of $60^{\circ} \mathrm{C}$ for one hour thirty minutes ( $1 \mathrm{hr} 30 \mathrm{mins}$ ) each to enable embedding. Tissues were transferred to moulds filled with molten paraffin wax. Once the paraffin wax cooled and hardened, the mould was removed, exposing a small paraffin block containing the sample tissue.The paraffin blocks were sectioned at ten micro metres $(10 \mu \mathrm{m})$ after cooling the surface of the tissues on ice.

\section{Haematoxylin and Eosin}

Tissue sections were taken to water by deparaffinising in 2 changes of xylene for 2 minutes each, followed by dehydration in 100\% alcohol, 95\% alcohol, 70\% alcohol twice for 5 minutes each and finally rinsed in tap water. Sections were stained with haematoxylin for 10 minutes, washed briefly in tap water, differentiated in acid alcohol, washed well in running tap water till blued. The blued sections were counterstained in eosin solution for 1 minute. Tissues were air dried and mounted in di-polycysteine xylene (DPX), covered with coverslips and observed under digital photomicrographic microscope.

\section{Immunohistochemical staining techniques}

Sections were deparaffinised using 2 changes of xylene (5 minutes each), followed by dehydration where sections were rinsed twice in $100 \%$ alcohol, 95\% alcohol, 70\% alcohol, 40\% alcohol for 5 minutes each and finally rinsed in tap water. Antigen retrieval was performed using citric acid solution ( $\mathrm{pH} 6.0$ ) in a microwave at power $100 \mathrm{~W}$ for 15 minutes, thereafter sections were equilibrated by gently displacing hot citric acid with water for 3 minutes. Peroxidase in the tissues was blocked using peroxidase block for 15 minutes. Sections were washed for 2 minutes using phosphate buffered saline (PBS) mixed with tween 20. Protein was blocked using Novocastra protein block for 15 minutes and sections washed in PBS for 2 minutes. Sections were incubated with primary anti GFAP for GFAP immunohistochemical studies, 1 in 100 dilutions for 45 minutes each, and sections washed with PBS for 3 minutes. Secondary antibody was added for 15 minutes and section washed twice with PBS. Polymer was added for 15 minutes and sections washed twice with PBS. Diaminobenzedine (DAB) was added for 5 minutes; sections washed with tap water, counterstained in haematoxylin for 2 minutes, washed, dehydrated, cleared and mounted on DPX.

\section{Cell count}

Five power fields snapped from cerebellum of animals in each group were counted using image J software. The results obtained were then analyzed using T-test. Values $<0.05$ were taken as significant.

\section{Results}

\section{Effect of lamivudine on weight of the rats}

There were no significant weight differences between the rats in the treatment and control group Table 1 .

\section{Histological results}

The photomicrograph of the slides obtained from each group is shown in Figures 1 and 2 for H\&E and Figures 3 and 4 for GFAP immunohistochemical method. $\mathrm{H} / \mathrm{E}$ staining showed perturbations in the cerebellum of the group B rats (Figure 2) with shrunken purkinje cells and distorted molecular layer. In general, the cells of the group B (Figure 2) rats were smaller compared to group A (Figure 1). GFAP Immunohistochemical staining also showed high expression of GFAP in the cerebellum of group B (Figure 4) rats compared to group A (Figure 3) rats.

\section{Cell count}

The result of cell count showed a significant reduction in cells in the Table 1. Effect of lamivudine on weight differences of the rats.

\begin{tabular}{|c|c|}
\hline Groups & Mean \pm SD of weight differences \\
\hline Control & $20.00 \pm 3.96$ \\
\hline Lamivudine & $17.00 \pm 3.61$ \\
\hline
\end{tabular}

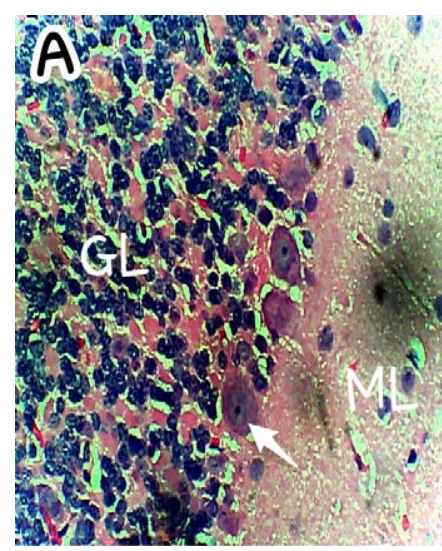

Figure 1. Photomicrograph of the histology of the cerebellum of the Control group (A) showing the three cerebellar cortical layers; molecular layer (ML), granular layer (GL), and the single-line Purkinje cells (arrow). Within the molecular layer the basket and stellate neuronal cells are well shown. No apparent abnormality is seen. H \& E $\times 400$.

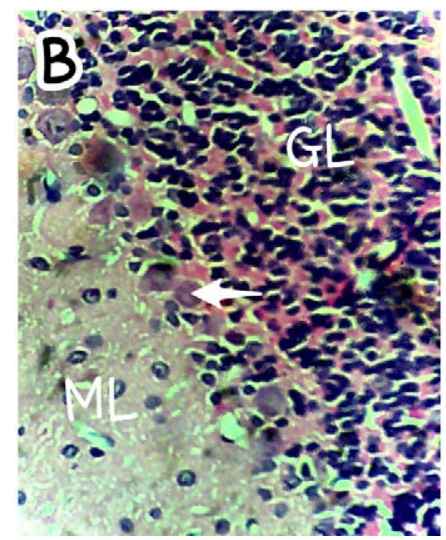

Figure 2. Photomicrograph of the histology of the cerebellum of group B (treated with $4.28 \mathrm{mg} / \mathrm{kg}$ of lamivudine) showing the three cerebellar cortical areas; a molecular layer (ML), a distorted granular layer (GL), with shrunken Purkinje cells (arrow). The Purkinje cells and granular cells appear smaller. H \& E, $\times 400$. 


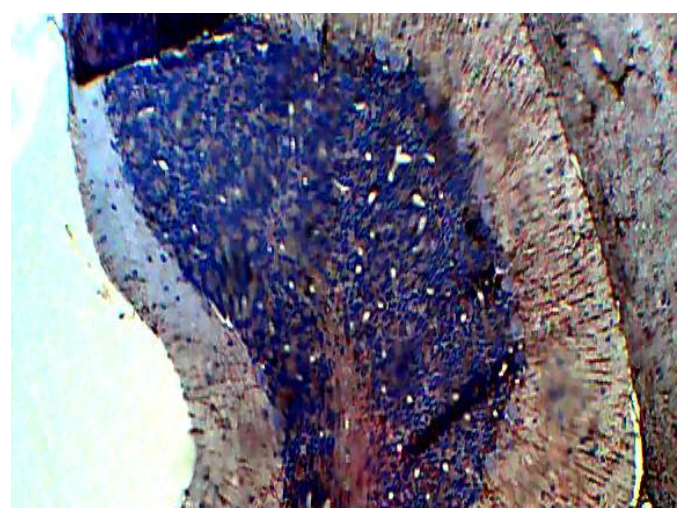

Figure 3. Photomicrograph of the histology of the cerebellum of the Control group (A) showing normal staining in GFAP immunohistochemistry, $\times 200$.

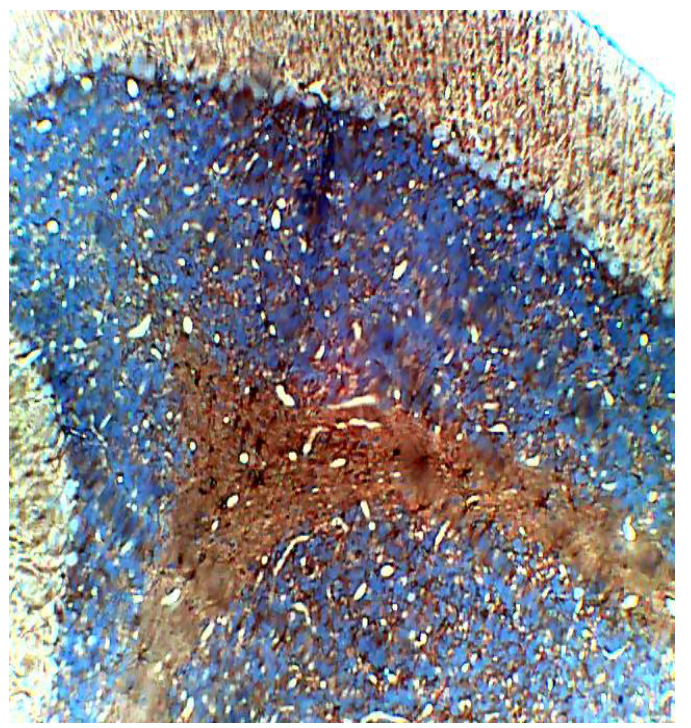

Figure 4. Photomicrograph of the histology of the cerebellum of group B (treated with $4.28 \mathrm{mg} / \mathrm{kg}$ of lamivudine) showing increased staining in GFAP immunohistochemistry, $\times$ 200 .

groups treated with lamivudine when compared with controls at 0.05 level of significant (Figure 5).

\section{Discussion}

The cerebellum is basically known for its coordination of somatic motor function, muscle tone, balance and equilibrium. However, elaborate investigation into the cerebellum has shown that it also plays a role in nonmotor activities of the brain such as cognition, emotions, behavior, and memory processes through its connections with other areas of the brain $[18,19]$. Cerebellar lesions have been known to be involved in pathological laughter and crying resulting from impaired emotional expression [20]. According to Ferrucci, et al. the cerebellum is involved in processing facial expression of negative emotions [21]. Therefore, injury to the cerebellum may result in abnormalities in control of voluntary movements and decrease in living standard of people living with HIV.

Findings from this study have shown that lamivudine had no effects on the weights of the rats (Table 1), but had a degenerative effect on the cells of the cerebellum as shown in figures $2 \& 4$ of group B rats compared to figures $1 \& 3$ of group A rats and cell count in Figure 5. Our findings corroborated with findings of Ferretti et al. which reported that cerebellar lesions occurred in MRI of patients under lamivudine

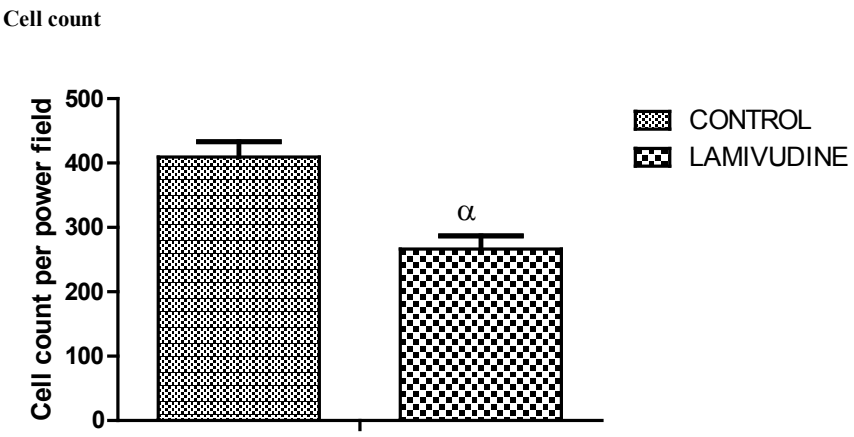

Figure 5. Cell count differences between control and Lamivudine treated groups.

containing combined anti-retroviral therapy [14]. High expression of GFAP by astrocytes and shrinkage of cells found in the molecular layer suggest cellular inflammation and loss of neuronal fibers. This may render the cerebellar connections ineffective and impair the modulatory function of the cerebellum on other brain centers [22]. This effect may be expressed as depression and dizziness which have been reported as side effects from lamivudine use. This possibility corresponds with the report by Tuner, et al. that cerebellar lesions are associated with reduced pleasant experience in stroke patients [22].

Given that lactic acidosis is a common side effect from lamivudine use, and Stelmashuk, et al. had reported that high concentrations of acid is toxic to granular cells of the cerebellum, it is possible that the damaging effect of lamivudine on the cerebellum could be secondary to a concomitant surge in lactic acidosis in the cerebellar environment during lamivudine therapy [17].

\section{Conclusion}

The effect of lamivudine on the histology of the cerebellum of Wistar rats was investigated in this study. H\&E and GFAP immunohistochemical staining showed that lamivudine induces cerebellar degeneration which may underlie some of the side effects (especially dizziness and depression) seen with the use of lamivudine. However, cerebellar degeneration maybe secondary to inducement of lactic acidosis by lamivudine. More research is needed to ascertain this, and also to understand the molecular mechanism of this degeneration. It is recommended that lamivudine be taken with neuro-protective drugs to ameliorate this effect.

\section{Funding}

The study was funded from the money raised by the authors for the sole purpose of the investigation carried out herewith.

\section{Competing interest}

The authors declare that there is no competing interest of any kind related to the study.

\section{References}

1. Liaw YF, Sung JJ, Chow WC, Farrell G, Lee CZ, et al. (2004) Lamivudine for patients with chronic hepatitis B and advanced liver disease. N Engl J Med 351: 1521-1531. [Crossref]

2. Ranbaxy (2006) Sonke-Lamivudine and Zidovudine tablets. pharmaceutical Industry.

3. Taglione MS, Ahmad H, Slater M, Aliarzadeh B, Glazier RH, et al. (2017) Development of a preliminary essential medicines list for Canada. CMAJ Open 5: E137-137E143. [Crossref]

4. Drugs.com (2017) Lamivudine/zidovudine Side Effects in Detail. 
5. Hagberg L,Cinque P, Gisslen M, Brew BJ, Spudich S, et al. (2010) Cerebrospinal fluid neopterin? an informative biomarker of central nervous system immune activation in HIV-1 infection. AIDS Res Ther 7: 1-12. [Crossref]

6. Dienstag JL, Goldin RD, Heathcote EJ, Hann HW, Woessner M et al. (2003) Histological outcome during long-term lamivudine therapy. Gastroenterology 124 105-117. [Crossref]

7. Cohen E (2014) Doctor treats Ebola with HIV drug in Liberia--seemingly successfully. $C N N$ : 2014-2017.

8. Drugs.com (2016) Lamivudine and Zidovudine tablets - FDA prescribing information, side effects and uses.

9. Moyle GJ, Gazzard BG (2001) Differing reverse transcriptase mutation patterns in individuals experiencing viral rebound on first-line regimens with stavudine/didanosine and stavudine/lamivudine. AIDS 15: 799-800. [Crossref]

10. Ene L, Duiculescu D, Ruta SM (2011) How much do antiretroviral drugs penetrate into the central nervous system? J Med Life 4: 432-439.[Crossref]

11. Letendre SL, McCutchan JA, Childers ME, Woods SP, Lazzaretto D (2004) Enhancing antiretroviral therapy for human immunodeficiency virus cognitive disorders. Ann of Neurol 56: 416-423.[Crossref]

12. Cunninham PH, Smith DG, Satchell C, Cooper DA, Brew BJ (2016) Evidence for independent development of resistance to HIV - 1 reverse transcriptase inhibitors in the cerebrospinal fluid. AIDS 14: 1949-1954.

13. Li J, Xiong GE, Huang Z, Li G, Xiao BO, et al. (2007) Parkinsonism with long term use of lamivudine. Neurol Asia 12: 111-113.
14. Ferretti F, Gerevini S, Colombo B, Testa M, Guffanti M, et al. (2013) Susac's syndrome as HIV-associated immune reconstitution inflammatory syndrome. AIDS Res Ther 10: 22.[Crossref]

15. Kowlgi NG, Chhabra L (2015) D-lactic acidosis: an underrecognized complication of short bowel syndrome. Gastroenterol Res Pract 2015: 476215.[Crossref]

16. Challa VR, Markesbery WR, Baumann RJ, Noonan JA (1978) Lactic Acidosis Associated with Cerebellar Vermal Atrophy and Cardiomyopathy. Neuropediatrics 9: 277-284.

17. Stelmashuk EV, Belyaeva EA, Isaev NK (2007) Effect of Acidosis, Oxidative Stress, and Glutamate Toxicity on the Survival of Mature and Immature. Neurochemical Journal 1: 66-69.

18. Konarski JZ, McIntyre RS, Grupp LA, Kennedy SH (2005) Is the cerebellum relevant in the circuitry of neuropsychiatric disorders? J Psychiatry Neurosci 30: 178-186. [Crossref]

19. Schmahmann JD (2000) The role of the cerebellum in affect and psychosis. $J$ Neurolinguistics 13: 189-214.

20. Parvizi J, Anderson SW, Martin CO, Damasio H, Damasio AR (2001) Pathological laughter and crying: a link to the cerebellum. Brain 124: 1708-1719.[Crossref]

21. Ferrucci R,Giannicola G, Rosa M, Fumagalli M, Boggio PS, et al. (2012) Cerebellum and processing of negative facial emotions: Cerebellar transcranial DC stimulation specifically enhances the emotional recognition of facial anger and sadness. Cogn Emot 26: 786-799. [Crossref]

22. Turner BM, Paradiso S, Marvel CL, Pierson R, Boles Ponto LL, et al. (2007) The cerebellum and emotional experience. Neuropsychologia 45: 1331-1341.[Crossref]

Copyright: $($ C2017 Peter AI. This is an open-access article distributed under the terms of the Creative Commons Attribution License, which permits unrestricted use, distribution, and reproduction in any medium, provided the original author and source are credited. 